\title{
ТРУДОВАЯ МОБИЛИЗАЦИЯ КАК СОСТАВНАЯ ЧАСТЬ ПОВСЕДНЕВНОСТИ ГРАЖДАНСКОГО НАСЕЛЕНИЯ ЕВРОПЫ В УСЛОВИЯХ ВТОРОЙ МИРОВОЙ ВОЙНЫ (НА ПРИМЕРЕ ГЕРМАНИИ, ВЕЛИКОБРИТАНИИ И СОВЕТСКОГО СОЮЗА)
}

\section{LABOR MOBILIZATION AS AN INTEGRAL PART OF THE EVERYDAY LIFE OF THE EUROPEAN CIVILIAN POPULATION IN THE SECOND WORLD WAR (ON THE EXAMPLE OF GERMANY, GREAT BRITAIN AND THE SOVIET UNION)}

\section{Emirkhanov}

Summary: The article is devoted to the analysis of measures taken by the governments of Germany, Great Britain and the USSR during the Second World War, the purpose of which was to mobilize labor resources to achieve victory over the enemy. The author makes a comprehensive analysis of various problems related to the introduction of labor conscription for the population of the three leading European powers that took an active part in the Second World War. The relevance of the research is due to the increased interest in various aspects of the history of the Second World War, including in the social sphere, such as the life of the common man, his working conditions during the years of military everyday life. The article is based mainly on Russian works published in recent years.

Keywords: labor mobilization, World War II, Germany, Great Britain, USSR, labor force, military production.

\author{
Эмирханов Исмаил Асланович \\ к.и.н., доцент, Дагестанский государственный \\ университет (2. Махачкала) \\ historik2008@yandex.ru
}

Аннотация: Статья посвящена изучению мер, проведенных правительствами Германии, Великобритании и СССР в годы Второй мировой войны, целью которых являлась мобилизация трудовых ресурсов для достижения победы над противником. Автор проанализировал различные проблемы, связанные с введением трудовой повинности для населения трех ведущих европейских держав, принявших активное участие в войне. Актуальность исследования обусловлена повышенным интересом к различным аспектам истории Второй мировой войны, в том числе в социальной сфере, таким как жизнь простого человека, условиям его труда в годы военной повседневности. Статья опирается преимущественно на российские исследования, изданные в последние годы.

Ключевые слова: трудовая мобилизация, Вторая мировая война, Германия, Великобритания, СССР, рабочая сила, военное производство.
$\mathrm{B}$ последние годы появилась тенденция к пересмотру и переоценке некоторых проблем истории Второй мировой войны, что обусловлено введением в научный оборот ранее недоступных простому читателю источников и появлением в отечественной и зарубежной историографии новых работ, посвященных данной теме. Историки ставят перед собой новые задачи, открывают для темы и исследовательские поля, которые раньше из-за идеологических, политических или иных мотивов были закрыты.

Одним из таких направлений является изучение различных аспектов истории повседневности гражданского населения в условиях Второй мировой войны, в частности, к малоизученной можно отнести проблему человека тыла, осуществлявшего каждодневную трудовую деятельность. Трудовые отношения в отмеченный период приобрели специфический характер, в совокуп- ности механизмы их регулирования были направлены на мобилизацию рабочей силы воюющих стран, направленной, в первую очередь, на обеспечение фронта всей необходимой продукцией.

\section{Германия}

Накануне мирового конфликта нацистским руководством был разработан комплекс чрезвычайных мер, направленных на обеспечение полного переключения ресурсов Третьего Рейха, союзных и оккупированных государств на ведение войны до победного конца. Это подразумевало полный пересмотр требований к экономике, а также мобилизацию всех людских и материальных сил. Германские власти приучали немцев к мысли, что военные действия будут продолжительными и жестокими, требующими больших жертв и громадного напряжения сил. Так, еще в июне 1935 года нацистское правительство 
подписало закон, в соответствии с которым трудовая повинность стала обязательной для всех немцев в возрасте от 19 до 25 лет. По мнению военного инженера Вальтера Кумп фа, этот документ должен был убедить немецкую молодежь «в нравственной ценности труда, ослабить классовые противоречия, уничтожить пренебрежительное отношение к простому ручному труду и усилить общественное сознание всех слоев населения» [16, с. 394]. Нацистские власти считали, что трудовую повинность можно рассматривать в качестве способа решения проблемы перевооружения и безработицы. По их мнению, немец, умеющий работать с лопатой, может без проблем справиться и с оружием. Таким образом, во время работы в трудовых лагерях юноши и девушки превращались в практически бесплатную рабочую силу.

С началом войны большинство отрядов трудовой повинности в Германии превратились в строительные батальоны, которые занимались прокладкой и ремонтом дорог и путей, наведением временных мостов, строительством постоянных мостов, строительством и ремонтом аэродромов, складов продовольствия и военных материалов, разгрузкой эшелонов практически на всех театрах военных действий. То есть, с 1939 года трудовую повинность немцам заменили на обычную военную службу.

Мобилизация в германские вооруженные силы мужчин, особенно из сельскохозяйственных районов, обусловила дефицит трудовых ресурсов в деревне, замена которым была найдена в женских отрядах трудовой повинности. Немки помогали в работе по дому, ухаживали за детьми в многодетных крестьянских семьях: ходили за покупками, стирали, готовили и доставляли в поле обеды, гладили, штопали, проверяли домашние задания детей. Они помогали крестьянам сажать картофель, убирать урожай зерновых и корнеплодов, хмеля, винограда, заготавливать сено, «полоть сорняки, чистить навозные ямы, складывать брикеты или наполнять соломенные тюфяки» [5, с. 42]. Однако женские отряды не удовлетворяли возрастающий спрос государства в рабочей силе, их старались использовать преимущественно в аграрном секторе, в то время, как в промышленности удельный вес их был значительно низким.

К тому же, сам Гитлер выступал категорически против вербовки немецких женщин на военные предприятия, так как это могло нанести урон их детородным функциям, помешать иметь детей или заботиться о семье. Еще в 1942 г. он принял меры для обеспечения немецких женщин, которые добровольно трудоустраивались в военных учреждениях, относительно несложной работой. К 1944 г. более 3,5 млн женщин в Германии трудились неполный рабочий день, что в четыре раза превышало аналогичные показатели в Великобритании [17, с. 392].
Выход из положения был найден в использовании труда военнопленных и миллионов людей, пригнанных из оккупированных стран, которые составляли более 20\% рабочей силы в германской экономике. Их, практически рабский труд, использовался в тяжелой промышленности, а также в сельском хозяйстве. Поэтому, используя ресурсы оккупированных стран, нацисты не спешили ввести более жесткие условия работы военного времени для собственных граждан. В результате почти до конца 1942 года немцы воспринимали войну опосредованно: она шла где-то далеко за пределами Германии.

Однако после поражения войск вермахта под Сталинградом и Курском в 1943 г., нацисты перешли к политике тотальной мобилизации, которая связана с именем рейхсминистра вооружений и военного производства Германии Альберта Шпеера. Его план предусматривал мобилизацию на военное производство всех мужчин в возрасте от 16 до 65 лет и женщин от 17 до 45 лет. В соответствии с законом «О закрытии или слиянии предприятий и о запрещении некоторых отраслей промышленности», были закрыты много мелких предприятий и коммунальных учреждений. Только в Берлине было ликвидировано 5 тыс. торговых и 4 тыс. ремесленных предприятий [1, с. 22], работников которых направляли на военно-промышленные объекты.

Проведенная Шпеером тотальная мобилизация людских ресурсов позволила увеличить военное производство в Третьем Рейхе, а по выпуску основных видов промышленных товаров превысить уровень 1942 года. Однако принудительная трудовая мобилизация, хотя и создала условия для дальнейшего увеличения военного производства, не привела к существенному повышению германского военно-промышленного потенциала и победе в войне.

\section{Великобритания}

После начала Второй мировой войны правящие круги Великобритании направили все свои ресурсы на мобилизацию экономического, финансового и людского потенциала для разгрома Германии и ее союзников. В этой обстановке актуальной задачей правительства Туманного Альбиона стал перевод промышленности на военные рельсы для бесперебойного выпуска необходимой стратегической продукции, что подразумевало перевод под государственный контроль над вопросами регулирования и распределения не только стратегически важных видов сырья, топлива, продовольствия, но и трудовых ресурсов.

В результате произошла значительная трансформация различных сфер жизни британского общества, которая выразилась в принятии чрезвычайного военного законодательства, ограничивавшего гражданские права 
населения, а также в введении всеобщей трудовой повинности. Так, 25 мая 1940 года был принят закон «Об обороне», предоставивший британским властям право использования любого лица по своему усмотрению. Вдобавок контроль и регулирование в использовании рабочей силы предприятиями любой формы собственности перешел в руки Министерства труда и национальной повинности под руководством Э. Бевина. В соответствии же с законом о «Важных работах», принятым 5 марта 1941 г., рабочим запрещалось уходить с предприятий по своему усмотрению, а предприниматели не имели права увольнять рабочих без разрешения сотрудника Министерства труда и национальной повинности [3, с. 4]. Фактически это означало, что в случае необходимости государственные органы могли привлекать британцев на выполнение любых работ и использовать на свое усмотрение любую собственность и предприятия, то есть направлять рабочую силу на те промышленные объекты, продукция которых больше всего требовалась стране.

Военная действительность обусловила существенные изменения условий труда для промышленных рабочих, выражавшееся в росте его интенсификации, увеличении продолжительности рабочего времени и отмене выходных. К примеру, на авиационных заводах продолжительность рабочей смены составила 10 часов в день, а на некоторых оборонных предприятиях - 12 часов. Руководство заводов и фабрик было поставлено перед необходимостью создания приемлемых условий труда и гарантий определенного недельного заработка для рабочих [2, с. 512].

Стремительное увеличение объемов военной продукции с первых дней войны привело к значительному сокращению безработицы в стране. Если к лету 1940 г. в Великобритании было примерно 645 тыс. безработных, то в последующем была достигнута почти полная занятость. Однако из-за призыва на военную службу мужчин в возрасте от 18 до 51 года на большинстве военных предприятиях ощущалась нехватка рабочей силы, причем наиболее остро этот вопрос встал в конце 1941 г. [10, с. 191]. В результате британские власти повсеместно стали привлекать на производство женщин, причем нередко в принудительном порядке.

За период с 1939 по 1943 г. количество работающих женщин возросло с 5 до 8 млн. В 1943 г. удельный вес женщин на производстве составил 33\%, для примера - в 1939 г. таковых было около 14\%. Британкам приходилось выполнять различные работы, осваивать профессии сварщика, калибровщика, клепальщика и ряд других. В общем, к 1943 г. около 46\% от общего числа британских женщин в возрасте от 14 до 59 лет работала в промышленности или сельском хозяйстве [2, с. 513].

Необходимо отметить, что в условиях войны бри- танцы лояльно относились к ужесточению трудовой дисциплины, воспринимая ее как вынужденную необходимость. «В массах - среди рабочих, фермеров, лавочников, интеллигентов, в рядах «среднего класса», - отмечал видный британский политик Д. Ллойд Джордж, - есть мрачная решимость довести войну до конца» [14, с. 251]. Всех жителей Туманного Альбиона, невзирая на происхождение и возраст, объединила общая цель. «Сословные и имущественные различия были стёрты, - отмечает в своем исследовании Д.В. Суржик, - (в богатых домах исчезла прислуга). Все были равны перед немецкими бомбами, на службе ежедневно трудились рука об руку люди разного достатка и воспитания» [Там же].

Таким образом, в годы Второй мировой войны британские власти провели ряд мероприятий, направленных на решение проблемы увеличения трудовых ресурсов. В результате были подвергнуты изменениям нормы, касающиеся обеспечения предприятий рабочими руками. По британским законам всех рабочих прикрепили к предприятиям оборонной промышленности, кроме того, была проведена мобилизация трудоспособного населения для работы в промышленности. Одним из способов решения проблемы обеспечения предприятий трудовыми ресурсами в условиях войны стало повышение интенсификации труда британских рабочих, перевод большинства гражданских отраслей экономики на военные рельсы, а также вовлечение в сферу производства женщин.

\section{CCCP}

После начала Великой Отечественной войны перед советским руководством одной из первоочередных задач стала оперативная мобилизация всех имеющихся материальных и финансовых ресурсов для обеспечения победы над противником. С этой целью сталинским окружением во главу угла организации советской военной экономики был поставлен лозунг «Всё для фронта, всё для победы!». В результате были приняты ряд неотложных мер, такие как увеличение продолжительности рабочего дня, отменена ежегодных отпусков рабочих и служащих, объявление работников оборонных предприятий мобилизованными до конца войны, возврат в производство старых кадровых рабочих и др.

Ожесточенные бои и большие потери в живой силе потребовали увеличения численности Красной армии, что обусловило вывод из общественного производства значительной часть работоспособного мужского населения, массового перевода промышленных объектов на производство вооружения или другой военной продукции, а стало быть, усиления процесса притока гражданского населения тыловых регионов в предприятия оборонной промышленности. Причем в качестве основного метода привлечения рабочих рук, как на промышленные 
объекты, так и оборонительные работы, выступала принудительная мобилизация трудоспособного населения, не занятого в общественном производстве. Уже 22 июня 1941 года Президиум Верховного Совета СССР принял Указ «О военном положении», в соответствии с которым в районах, которые были объявлены на военном положении, власти получили право привлекать гражданское население к трудовой повинности [13, с. 11-13].

В условиях войны советское трудовое законодательство получило явный крен в сторону принудительной мобилизации людей на нужды оборонительного характера, а также усиление мер ответственности за правонарушения, дезертирство и дисциплинарные проступки в трудовой сфере. Свидетельством этого является Указ Президиума Верховного Совета СССР «О мобилизации на период военного времени трудоспособного городского населения для работы на производстве и строительстве» от 13 февраля 1942 года, в котором указывалось: «Признать необходимым на период военного времени мобилизацию трудоспособного городского населения для работы по месту жительства на производстве и строительстве...» [12].

Согласно документу мобилизации, подлежали все трудоспособные горожане: мужчины в возрасте от 16 до 55 лет и женщины от 16 до 45 лет, которые не работали в государственных учреждениях или на предприятиях. От призыва на трудовой фронт были освобождены мужчины и женщины в возрасте от 16 до 18 лет, направленных в школы фабрично-заводского обучения, ремесленные и железнодорожные училища, женщины, имевшие малолетних детей, а также студенты вузов и техникумов. В случае уклонения от трудовой мобилизации предусматривалась уголовная ответственность [6]. В результате сотни тысяч людей, преимущественно сельская молодежь, были направлены в различные отрасли народного хозяйства тыловых регионов страны.

Со второй половины 1942 г. советским руководством стали предприниматься дополнительные меры для привлечения в производство граждан, в первую очередь, для лиц, которые ранее не подпадали под категорию «мобилизованных». Так, в соответствии с постановлением СНК СССР от 28 августа 1942 г., неработающие инвалиды III группы (мужчин в возрасте до 55 лет и женщин в возрасте до 45 лет) стали трудоустраиваться по месту жительства на предприятиях и в учреждениях при наличии положительного заключения ВТЭК, а в случае их отказа предусматривалось прекращение выплаты пенсий $[11$, с. 81]. По сути, в годы войны советская власть перешла от экономических мер стимулирования труда к внеэкономическим, административно-принудительным, направленным на привлечение на обслуживание военных потребностей как можно большее число трудоспособного населения страны.
Однако нельзя утверждать, что военные годы характеризовались только ужесточением трудового законодательства и отсутствием заботы о рабочем контингенте промышленных объектов и других стратегически важных отраслей народного хозяйства. В условиях военного времени значительная часть рабочего контингента заводов и фабрик состояла из социально незащищенных категорий населения - женщин, а также несовершеннолетних граждан, в связи с чем принимались меры для охраны их труда и трудовых прав. Так, в соответствии с Указом Президиума Верховного Совета СССР одиноким и многодетным матерям полагались денежные пособия, единовременные пособия на новорожденных детей. Было запрещено использование беременных и кормящих женщин на ночных и сверхурочных работах; матерям, воспитывавшим детей в возрасте до восьми лет, полагался один выходной день в неделю [9, с. 104].

Однако в реальности, из-за нехватки рабочих рук, все предоставляемые государством социальные льготы женщины, которые практически полностью заменили мобилизованных на фронт мужчин, вынуждены были чуть ли не круглосуточно трудиться на заводах и фабриках, сооружении оборонительных рубежей на стратегически важных позициях, получали время от времени. С сентября 1942 г. трудовой мобилизации подлежали женщины уже в возрасте 50, вместо положенных ранее 45 лет [4, с. 79]. К тому же, зачастую, из-за опасения лишиться продуктовых талонов или работы, а также стремясь внести свой личный вклад в победу над врагом, женщины не пользовались предоставляемыми льготами.

Обострение обстановки на фронте привело к резкому увеличению интенсивности труда и в аграрном секторе страны, причем в первую очередь это касалось продолжительности рабочего времени и трудовых нагрузок. В сельской местности крестьяне традиционно не знали такого понятия как нормированный режим рабочего дня, который зависел от продолжительности светлого времени суток. В качестве примера можно привести выдержку из отчёта Староюрьевского райкома партии Тамбовской области за июль 1941 года, где было отмечено, что рабочий день для селян начинался в 4 часа утра и заканчивался затемно [15, с. 162].

В другом случае, по воспоминаниям крестьянки из деревни Чернавка Бондарского района Тамбовской области, молодые колхозницы вынуждены были вставать на работу в 3-4 часа, завершать рабочий день после наступления темноты, а уже спать укладываться около 10 часов ночи [8, с. 40]. Как отмечает отечественный исследователь, в годы военного лихолетья «ударный труд, активно пропагандируемый советской печатью, для многих действительно стал нормой поведения, законом жизни в условиях военного и послевоенного времени» [Там же]. Таким образом, трудовая мобилизация стала 
одним из основных факторов, которая определяла повседневную жизнь советских граждан в условиях войны.

Вторая мировая война, потребовавшая крайнего напряжения материальных и духовных ресурсов Германии, Великобритании и СССР, привела к изменению понятия о сущности мобилизации. Так, в дополнение к переводу армии на военные рельсы, обеспечивался переход народного хозяйства, социальных служб и системы управления на обеспечение потребностей фронта. Причем самым важным стала мобилизация экономического по- тенциала государства, подразумевавшая организованное использование ресурсов для ведения войны. В результате были разработаны особые мобилизационные планы, в соответствии с которыми на выпуск военной продукции переводилась львиная часть промышленных объектов, прежде ориентированных на изготовление товаров народного потребления. Власть пошла по пути введения всеобщей трудовой повинности, которая позволила в условиях военного времени решить проблему обеспечения оборонных отраслей промышленности рабочей силой.

\section{ЛИТЕРАТУРА}

1. Аникеев А.А. Тотальная мобилизация в нацистской Германии в годы Второй мировой войны // Гуманитарные и юридические исследования. 2017. №2. C. 21-25.

2. Великая Отечественная война 1941-1945 годов. В 12 т. Т. 9. Союзники СССР по антигитлеровской коалиции. М.: Кучково поле, 2014. - 864 с.

3. Гаврилов Д.В. Двойные стандарты в оценке внутренней политики стран антигитлеровской коалиции в годы Второй мировой войны // Военно-исторический журнал. 2012. №. 1 (621). - С. 3-9.

4. Гончаров Г.А. Трудовая политика советского государства в годы Великой Отечественной войны // Вестник Челябинского государственного университета. 2001. Т. 1. Вып.1. - С. 77-83.

5. Ермаков А.М. Имперская служба труда в германии в воспоминаниях ее участниц (2000-2003) // Ярославский педагогический вестник. 2005. №1 (42). C. 37-44.

6. Земсков В.Н. Организация рабочей силы и ужесточение трудового законодательства в годы войны с фашистской Германией // Политическое просвещение. 2014. №2(79). Электронный ресурс: https://www.politpros.com/journal/read/?lD=3167\&journal=157 (дата обращения 13.08.2020)

7. Кирсанов, Н.А. Кто помогал Гитлеру? Европа в войне против Советского Союза. М.: Вече, 2014. - 480 c.

8. Назаров А.И. Трудовая деятельность в повседневной жизни сельской молодёжи в советском тылу в период Великой Отечественной войны (на материалах Тамбовской области // Грамота. 2010. № 2 (33): в 2-х ч. Ч. І. - С. 40-43.

9. Нанаева М.А. Трудовая повседневность работников промышленности Ставропольского края на завершающем этапе Великой Отечественной войны // Ученые записки Российского государственного социального университета. 2007. №3. - С. 103-105.

10. Остапенко Г.С., Прокопов А.Ю. Новейшая история Великобритании XX - начало XXI века. М.: Инфра-М; Вузовский учебник, 2012. - 470 [1] с.

11. Писаренко И.С. Советское законодательство о трудоустройстве инвалидов во время Великой Отечественной войны // Актуальные проблемы гуманитарных и естественных наук. 2014. №7-1. - С. 78-85.

12. Президиум Верховного Совета СССР Указ от 13 февраля 1942 года «0 мобилизации на период военного времени трудоспособного городского населения для работы на производстве и строительстве». Электронный ресурс: http://www.consultant.ru/cons/cgi/online.cgi?req=doc\&base=ESU $\& n=4529 \# 04875787612093121$ (дата обращения 27.07.2020).

13. Русский архив: Великая Отечественная: Т. 13 (2-2). Приказы народного комиссара обороны СССР. 22 июня 1941 г. - 1942 г. М.: ТЕРPА, 1997. - 448 с.

14. Суржик Д.В. «Идемте вперед единой силой!». Британский тыл в годы Второй мировой войны. Часть 2 // Пространство и Время. 2015. Вып. 1-2 (19-20). - С. 241-251. Электронный ресурс: https://cyberleninka.ru/article/n/idemte-vpered-edinoy-siloy-britanskiy-tyl-v-gody-vtoroy-mirovoy-voyny-chast-2 (дата обращения 29.07.2020)

15. Тальцев А.Н. Трудовая мобилизация в повседневной жизни жителей (таврополья в годы Великой Отечественной войны // Вестник ТГПУ. 2018. №5 (194). - C. $157-165$.

16. Типпельскирх К., Кессельринг А. и др. Итоги Второй мировой войны. Выводы побеждённых. СПб.: Полигон; М.: АСТ, 1998. - 640 с.

17. Эванс Р. Третий рейх. Дни войны. 1939-1945. Пер. с англ. А.Л. Уткина. Екатеринбург: У-Фактория; М.: Астрель, 2011. - 942 [2] с.

(c) Эмирханов Исмаил Асланович (historik2008@yandex.ru). 